\title{
(5)
}

\section{APROXIMAÇÕES DO SERVIÇO SOCIAL COM A POLÍTICA DE EDUCAÇÃO: A CONTRIBUIÇÃO DAS COMISSÕES DE EDUCAÇÃO DOS CONSELHOS REGIONAIS DE SERVIÇO SOCIAL NO BRASIL}

\author{
Approaches of social service to the education policy: \\ the contribution of the education commissions of the Regional \\ Social Service Councils in Brazil \\ Adriana Freire Pereira Férriz ${ }^{*}$ \\ http://orcid.org/0000-0003-0819-7779 \\ Eliana Bolorino Canteiro Martins** \\ http://orcid.org/0000-0002-7796-8437
}

\begin{abstract}
RESUMO
O texto apresenta uma discussão sobre as aproximações entre o Serviço Social e a políticade educação, com foco na atuação das entidades da categoria neste contexto: Conjunto CFESS-CRESS (Conselho Federal de Serviço Social - Conselho Regional de Serviço Social), Associação Brasileira de Ensino e Pesquisa em Serviço Social (ABEPSS) e Executiva Nacional de Estudantes de Serviço Social (ENESSO). O objetivo central foi pautar as comissões de educação dos CRESS em todo o País e destacar o papel que essas comissões assumem não só no processo de organização dos profissionais na política de educação, mas também na luta por inserção de mais profissionais nessa política. A metodologia contemplou a coleta de dados junto aos sites dos CRESS disponíveis e o contato com profissionais que atuam na política de educação. Dessa forma, pretende-se mobilizar ações coletivas visando construir estratégias em prol do fortalecimento da luta por uma educação pública, laica, socialmente referendada, e como direito social, de forma articulada com as entidades que historicamente estabelecem a direção sociopolítica da profissão.
\end{abstract}

PALAVRAS-CHAVE

Educação. Serviço Social. Entidades da categoria.

\footnotetext{
*Assistente Social. Doutorado em Sociologia. Professora do curso de Serviço Social e do Programa de PósGraduação em Serviço Social da Universidade Federal da Bahia (2013-atual). (UFBA, Salvador, Brasil). Rua Aristides Novis, n.297, Federação, Salvador(BA).E-mail: adriana.ferriz@ufba.br.

**Assistente social. Doutorado em Serviço Social. Professora do curso de Serviço Social e do Programa de Pós-Graduação em Serviço Social da Universidade Estadual Paulista Júlio de Mesquita Filho (UNESP), Faculdade de Ciências Humanas e Sociais- Campus Franca (2010-atual). (UNESP, Franca, Brasil). Av. Eufrásio M. Petráglia, n. 900, Jardim Petráglia, Franca (SP). E-mail: elianacanteiro@terra.com.br.
}

DOI 10.22422/temporalis.2020V20n39p209-224

A(s) Autora(s)/O(s) Autor(es). 2019 Acesso Aberto Esta obra está licenciada sob os termos da Licença Creative Commons Atribuição 4.0 Internacional (https://creativecommons.org/licenses/by/4.o/deed.pt_BR), que permite copiar e redistribuir o material em qualquer suporte ou formato, bem como adaptar, transformar e criar a partir deste material para qualquer fim, mesmo que comercial. O licenciante não pode revogar estes direitos desde que você respeite os termos da licença.

Temporalis, Brasília (DF), ano 20, n. 39, p. 209-224, jan./jun. 2020. | ISSN 2238-1856 


\begin{abstract}
The text presents a discussion on the approximations between Social Service and education policy, focusing on the performance of the category entities in this context: CFESS-CRESS Group (Federal Council of Social Service - Regional Council of Social Service), Brazilian Education Association and Research in Social Work (ABEPSS) and National Executive of Social Work Students (ENESSO). The central objective was to guide the CRESS education commissions across the country and highlight the role that these commissions assume not only in the process of organizing professionals in education policy, but also in the struggle to insert more professionals into this policy. The methodology included the collection of data from the CRESS websites available and contact with professionals working in education policy. Thus, it is intended to mobilize collective actions to build strategies in favor of strengthening the fight for public education, secular, socially endorsed, and as a social right, in an articulated manner with the entities that historically establish the socio-political direction of the profession
\end{abstract}

\title{
KEYWORDS
}

Education. Social service. Category entities.

Submetido em: 2/4/2019.

Aceito em:4/11/2019.

\section{INTRODUÇÃO}

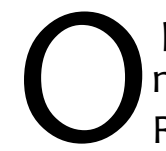

presente artigo faz uma discussão sobre a atuação das entidades da categoria neste contexto: o Conjunto Conselho Federal de Serviço Social (CFESS) - Conselho Regional de Serviço Social (CRESS), a Associação Brasileira de Ensino e Pesquisa em Serviço Social (ABEPSS) e a Executiva Nacional de Estudantes de Serviço Social (ENESSO), com destaque para as comissões de educação em atividade nos CRESS.

O objetivo central foi pautar as comissões de educação dos CRESS em todo o País e destacar o papel que essas comissões assumem não só no processo de organização dos profissionais na política de educação, mas também na luta por inserção de mais profissionais nessa política.

O interesse pelo tema surgiu do amplo debate que o Grupo de Estudos e Pesquisas sobre Serviço Social na Educação (GEPESSE) tem realizado sobre o tema Serviço Social na Educação, bem como da experiência vivenciada pelas autoras (integrantes do GEPESSE) nas Comissões de Educação do CRESS, principalmente na mobilização realizada pelo conjunto CFESS/CRESS em 2011/2012, que culminou na efetivação do I Encontro Nacional de Serviço Social, em Maceió (AL) (2012).

Sintonizado com o movimento da realidade social, constata-se que, nas últimas décadas, houve um recrudescimento da inserção dos assistentes sociais no âmbito da política de educação pública e privada, principalmente na educação básica (infantil e fundamental), no ensino superior e na educação profissional. Conforme afirma Almeida (2004), essa inserção dos assistentes sociais como componente teórico, político e ideológico é uma resposta, não-universal, do Estado às pressões das lutas sociais.

O GEPESSE vem realizando várias pesquisas no sentido de elucidar as particularidades e tendências da política educacional e da atuação profissional. Entre elas, destaca-se uma pesquisa que abrange os estados de São Paulo, Rio de Janeiro, Bahia e Paraíba, com o objetivo de analisar o trabalho profissional dos assistentes sociais nas principais experiências profissionais do Serviço Social na área da educação básica e de contribuir para o processo de sistematização dessas experiências, a fim de fortalecer o trabalho profissional dos assistentes sociais nesses espaços sócio-ocupacionais. 


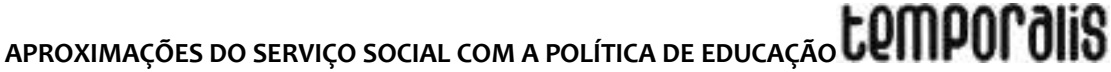

A análise da conjuntura atual e a aproximação que vem sendo realizada com os assistentes sociais que atuam na área da educação indicam a imperiosa necessidade de se construir estratégias de resistência para enfrentar as adversidades que incidem sobre a política de educação brasileira, especificamente sobre a profissão. É nesse sentido que nos debruçamos sobre a coleta de informações referentes à existência de Comissões de Educação no conjunto CFESS/CRESS, adotando como metodologia a investigação dos sites das entidades representativas da categoria profissional e o contato com assistentes sociais que atuam nessa política social.

Para atingir o objetivo proposto, o primeiro item do artigo traz uma apresentação e uma breve retrospectiva do papel das entidades da categoria de assistentes sociais no debate sobre a educação. $O$ item subsequente demonstra as atribuições das Comissões de Educação dos Conselhos Regionais de Serviço Social e o resultado da pesquisa com o panorama nacional da situação da atividade desses espaços coletivos. Em seguida, são apresentadas as considerações finais.

\section{O PAPEL DAS ENTIDADES DA CATEGORIA NO DEBATE SOBRE A EDUCAÇÃO}

A profissão de Serviço Social no Brasil possui mais de 80 anos de existência. Em termos sócio-históricos, portanto, é possível considerá-la uma profissão extremamente “jovem”. Contudo, ao se resgatar sua trajetória, algo empreendido com profunda densidade teórica por lamamoto e Carvalho (1982), entre outros, sob a égide do materialismo históricodialético, constata-se a intensidade do seu processo de transformação ao longo do tempo, culminando na construção de um projeto de profissão denominado Projeto Ético-Político Profissional. Tal projeto, aliás, é explícito quanto aos seus compromissos, pois,

[...] tem em seu núcleo o reconhecimento da liberdade como valor ético central a liberdade concebida historicamente, como possibilidade de escolher entre alternativas concretas; daí um compromisso com a autonomia, a emancipação e a plena expansão dos indivíduos sociais. Consequentemente, o projeto profissional vinculasse a um projeto societário que propõe a construção de uma nova ordem social, sem dominação e/ou exploração de classe, etnia e gênero. (NETTO, 1999, p. 104-105).

Uma particularidade da categoria profissional de assistentes sociais é a sua organização política, cunhada em um processo democrático que envolve os profissionais e os estudantes de Serviço Social nas diferentes entidades representativas dessa categoria, ou seja, no conjunto CFESS/CRESS, na ABEPSS e na ENESSO.

A proposta desse artigo é fazer um breve resgate da gênese e das atribuições dessas entidades representativas que, muitas vezes, fogem às nossas memórias, sendo que a intenção é colocar em relevo a significativa contribuição dessas instâncias no processo de fortalecimento da luta pela inserção do Serviço Social no âmbito da política de educação.

O conjunto CFESS/CRESS foi regulamentado no Decreto n. 994/1962, complementando a primeira Lei de Regulamentação da Profissão - Serviço Social (Lei n. 3.252/1957), recentemente alterada pela Lei n. 8.662/1993 (BRASIL [2011]). Esta assegura as competências e atribuições privativas do profissional e também garante a disciplina e a defesa do exercício profissional do assistente social. Assim, o CFESS é uma autarquia

Temporalis, Brasília (DF), ano 20, n. 39, p. 209-224, jan./jun. 2020. | ISSN 2238-1856 
pública federal que tem como principal atribuição orientar, disciplinar, normatizar, fiscalizar e defender o exercício profissional dos assistentes sociais no Brasil. ${ }^{1}$

O CFESS possui uma estrutura de organização que comporta 27 Conselhos Regionais de Serviço Social, que são responsáveis pelo desenvolvimento das políticas elaboradas e aprovadas pelo conjunto CFESS/CRESS, com intuito de estreitar a interação com a categoria profissional (CONSELHO FEDERAL DESERVIÇO SOCIAL, 2019).

A antiga Associação Brasileira de Escolas de Serviço Social (ABESS) foi criada em 1946, pouco mais de uma década após a implantação do primeiro curso de Serviço Social no Brasil, na Universidade Católica de São Paulo (PUC/SP), em 1932.

Posteriormente à realização do III Congresso Brasileiro de Serviço Social, conhecido como Congresso da Virada, ocorre em 1979 a convenção da ABESS, que assume a atribuição de coordenar e articular o projeto de formação profissional em Serviço Social. Essa entidade, então, contribui significativamente para o debate do processo de formação profissional em Serviço Social, sintonizada com o processo de amadurecimento teórico-metodológico e ético-político da profissão.

O currículo mínimo de 1982 e, posteriormente, a constituição das Diretrizes Curriculares para os Cursos de Serviço Social, em 1996, são expressões do movimento dessa instituição para garantir uma formação profissional coerente com o Projeto Ético-Político Profissional que foi sendo delineado ao longo do tempo pelo empenho dos profissionais - assistentes sociais e estudantes de Serviço Social.

Na segunda metade da década de 1990, em decorrência das discussões referentes ao processo de formação profissional dos assistentes sociais na defesa dos princípios da indissociabilidade entre ensino, pesquisa e extensão; da articulação da graduação com a pós-graduação; e da necessidade de articulação da pesquisa, há uma alteração da nomenclatura da entidade, que passou a chamar-se Associação Brasileira de Ensino e Pesquisa em Serviço Social.

A ABEPSS investe esforços para o acompanhamento permanente do processo de formação profissional dos assistentes sociais nas Unidades de Formação Acadêmicas (UFAs) públicas e/ou privadas existentes em todo território nacional. Por meio da mobilização de um debate democrático, docentes, discentes e gestores refletem sobre os projetos político-pedagógicos dessas unidades de ensino.

Expressivo exemplo de organicidade no fortalecimento da produção do conhecimento em Serviço Social realizada pela ABEPSS é a realização do Encontro Nacional de Pesquisadores em Serviço Social (ENPESS), que ocorre a cada dois anos. Além disso, há também as Oficinas Nacionais e Regionais de Graduação e Pós-Graduação, que se configuram como um debate político-acadêmico promissor. Vale ressaltar, ainda, que a ABEPSS é filiada à Asociación Latinoamericana de Enseñanza e Investigación en Trabajo Social (ALAEITS).

\footnotetext{
${ }^{1} \mathrm{O}$ artigo $8^{\circ}$ da Lei n. 8.662/1993, que regulamenta a profissão de Serviço Social, estabelece a competência do CFESS, na qualidade de órgão normativo de grau superior, as suas atribuições. (Lei n. 8.662/1993) (BRASIL, [2011]).
}

Temporalis, Brasília (DF), ano 20, n. 39, p. 209-224, jan./jun. 2020. | ISSN 2238-1856 


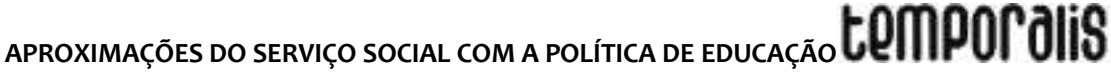

Para além dessas prerrogativas, principalmente nas últimas décadas, a ABEPSS tem propiciado espaços de debate e de formação permanente dos assistentes sociais, com a participação também de estudantes de Serviço Social no projeto denominado ABEPSS ITINERANTE, uma iniciativa da entidade que tem por objetivo:

\begin{abstract}
Fortalecer as estratégias político-pedagógicas de enfrentamento à precarização do ensino superior, por meio da difusão ampla dos princípios, conteúdos e desafios colocados para a consolidação das Diretrizes Curriculares como instrumento fundamental na formação de novos profissionais, na direção do plano de lutas em defesa do trabalho e da formação e contra a precarização do ensino superior (ASSOCIAÇÃO BRASILEIRA DE ENSINO E PESQUISA EM SERVIÇO SOCIAL, 2018, p. 2).
\end{abstract}

Os indícios da organização estudantil do Serviço Social já se encontravam presentes na década de 1960, especialmente a partir de 1961, com o Encontro Nacional de Estudantes de Serviço Social (ENESS). O ENESS, no entanto, foi interrompido em 1968 em decorrência da aprovação do Ato Institucional n. 5, que, entre outras questões, estabelecia a suspensão dos direitos políticos, tendo como justificativa a manutenção da ordem econômica, política, social e cultural e dos princípios estabelecidos pela Revolução de 31 de março de 1964. Enfim, procedimento peculiar na vigência da Ditadura Militar no Brasil.

Ainda assim, essa primeira articulação dos estudantes de Serviço Social já indicava a mobilização e o interesse da organização política desses jovens, mesmo diante de uma conjuntura extremamente conservadora. Somente dez anos depois, em 1978, com a queda do Al 5, é que ocorreu de fato o Encontro Nacional de Estudantes de Serviço Social, sendo considerado o I ENESS, realizado na Universidade Estadual de Londrina-PR. Nesse momento histórico, de desejo de retomada da democracia, e no bojo do processo de renovação do Serviço Social, o movimento de estudantes de Serviço Social reorganiza-se e, precisamente em 1981, começa a discutir a criação da Subsecretaria de Serviço Social (SESSUNE) na União Nacional de Estudantes (UNE). No mesmo ano é realizado o Congresso Nacional de Estudantes de Serviço Social (CONESS), na PUC/SP, e o IV Encontro Nacional de Estudantes de Serviço Social (ENESS), na Universidade Federal de Pernambuco.

Fato que marcou consideravelmente o Movimento de Estudantes de Serviço Social (MESS) foi a mudança da denominação SESSUNE para ENESSO, em 1993 - algo resultante de um processo de debates no MESS, consubstanciando uma maior autonomia desta organização estudantil perante a UNE. No mesmo ano, ocorreu ainda a criação da Secretaria de Formação Profissional e da Coordenação Nacional de Representação Estudantil na então denominada ABESS.

Há uma estreita relação entre a ABEPSS e a ENESSO, apesar de serem entidades de natureza diferentes; a ABPESS é uma entidade de ensino, pesquisa e extensão em Serviço Social que conta com a participação de estudantes de Serviço Social, e a ENESSO é uma entidade de estudantes, sendo imprescindível uma relação política e não-fisiológica entre elas. É importante reforçar que a ENESSO historicamente firmou sua legitimidade política perante a sociedade na definição dos rumos da formação profissional do assistente social no Brasil. Essas representações desenvolvem um trabalho articulado em defesa do projeto ético-político profissional, sempre com intuito de fortalecer as lutas do Movimento Estudantil em Serviço Social (MESS). 
A Associação Brasileira de Ensino e Pesquisa em Serviço Social se incumbe de coordenar o debate sobre o projeto de formação profissional, o conjunto CFESS/CRESS cumpre a responsabilidade pela fiscalização do exercício profissional e a ENESSO dirige a mobilização do movimento estudantil; assim, tais entidades

[...] materializam uma ação política que é um dos fatores que garantem a possibilidade de manutenção da direção social deste projeto coletivo que se vincula a um projeto societário comprometido com o fim da exploração/dominação dos seres humanos, ou seja, com a emancipação humana (RAMOS, 2011, p. 114).

Para além das pautas específicas dos assistentes sociais e estudantes de Serviço Social, é notório o comprometimento dessas entidades com as lutas que emergem no cenário da sociabilidade capitalista, da relação contraditória entre capital e trabalho, sempre na direção do Projeto Ético-Político Profissional, hegemônico no Serviço Social brasileiro. (RAMOS, 2011). Por meio de um debate teórico-prático, essas entidades trazem temas polêmicos, desvelando a ideologia dominante, explicitando o posicionamento da categoria profissional e demarcando a sua direção social e política.

Diante do exposto, em relação ao tema proposto para artigo, destaca-se a importante contribuição do conjunto CFESS/CRESS, da ABEPSS e da ENESSO na luta pelo Serviço Social na educação.

No debate sobre Serviço Social na Educação, principalmente nas últimas décadas, é primordial reconhecermos a importância dos órgãos representativos da categoria profissional. De forma específica, destaca-se o empenho desses órgãos na luta pela educação pública, laica, gratuita, de qualidade socialmente referendada, para todos. Ressalta-se, ainda, que essas instituições são fortes articuladoras e incentivadoras da discussão sobre o Serviço Social na educação e, além disso, são também fundamentais para que seja possível a aprovação de projetos de lei que visam à inserção do/a assistente social na área da educação.

Assim, para conjecturar sobre o fortalecimento do Serviço Social na educação e sobre a luta em prol da educação pública, é primordial estabelecer um diálogo com as entidades representativas do Serviço Social - o conjunto CFESS/CRESS, a ABEPSS e também a representação estudantil, por meio da ENESSO. Dessa maneira, são evidentes o empenho despendido e o posicionamento político dos órgãos representativos da categoria profissional na construção de estratégias de luta e resistência na defesa de uma sociedade mais justa e igualitária.

Podemos considerar que a primeira aproximação do Serviço Social com a educação se constituiu pelo próprio processo de formação profissional, sendo esse campo objeto de intensos e densos estudos, pesquisas e movimentos de luta buscando uma educação de qualidade ao longo da trajetória histórica do Serviço Social. Esse empenho tem exigido exaustivo esforço, principalmente nas últimas décadas, para conciliar uma formação profissional condizente com o amadurecimento teórico-metodológico, técnico-operativo e ético-político da profissão; em consonância, portanto, com o Projeto Ético-Político Profissional construído coletivamente, em tempos tão adversos. 


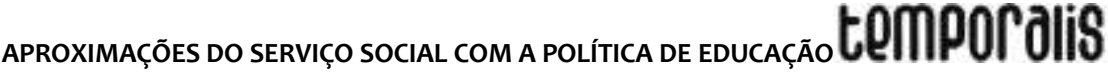

Faz-se necessário relembrar a construção e efetivação das Diretrizes Gerais para os Cursos de Serviço Social - aprovada na assembleia da ABEPSS, em 1996, fruto de um ciclo coletivo de debates acerca da direção social da formação profissional dos assistentes sociais brasileiros. Notadamente, nas últimas décadas, a Política de Educação brasileira tem sofrido os reflexos do ideário neoliberal, com o sucateamento do ensino superior público, a expansão desenfreada do setor privado com vistas à mercantilização da educação superior sob a ótica do capital. Nessa direção, emergiu na profissão, principalmente a partir da década de 1990, a criação de Cursos de Serviço Social na modalidade de Educação à Distância (EAD), invertendo a formação que prima pela qualidade para uma formação extremamente frágil, meramente tecnicista, avessa às prerrogativas anunciadas nas Diretrizes Gerais para os Cursos de Serviço Social. Assim,

\begin{abstract}
constata-se a realidade brutal de mercantilização da formação profissional em Serviço Social, o que aponta para a erosão do projeto de formação profissional dos assistentes sociais brasileiros construído sob a direção da ABEPSS na primeira metade dos anos 1990. Ao que tudo indica, a mercantilização da formação profissional de novos assistentes sociais atende, de um lado, as necessidades expansionistas do capital, e, de outro, a premência de formação do consenso entre as massas populares, o que exige a formação de intelectuais difusores da ideologia colaboracionista sob a ótica do capital, dentre eles o assistente social (CONSELHO FEDERAL DE SERVIÇO SOCIAL, 2012, p. 195).
\end{abstract}

Registra-se nesse campo o movimento de resistência da categoria profissional por meio dos órgãos representativos ABPESS e ENESSO, em um esforço conjunto na luta contra a educação bancária e mercantilizada, que não garante uma formação de qualidade para os futuros assistentes sociais. Considerando a necessidade de aprofundamento do debate para propor estratégias de resistências, principalmente sobre a questão da educação na modalidade à distância (EAD), em setembro de 2008, a partir do $37^{\circ}$ Encontro Nacional, o conjunto CFESS/CRESS instituiu o Grupo de Trabalho e Formação Profissional, com representações de profissionais dos CRESS de cada região do país e representantes das direções nacionais da ABEPSS e da ENESSO. O Grupo de Trabalho e Formação Profissional surge com o intuito de construir e monitorar a implementação de um Plano de Lutas em defesa do trabalho e da formação profissional do/a assistente social, bem como de evitar a precarização do Ensino Superior, considerando as mudanças da Lei de Diretrizes e Bases Nacionais - LDB/1996.

Esse processo de luta na defesa da universidade pública, gratuita, laica, de qualidade e socialmente referendada, tem sido foco de investimento do conjunto CFESS/CRESS, efetivando parcerias com o Sindicato Nacional de Docentes das Instituições de Ensino Superior (ANDES-SN) e com a ABPESS.

Outro aspecto, de aproximação teórica e prática do Serviço Social com o campo educacional, refere-se à dimensão educativa do seu trabalho profissional, que, segundo Cardoso e Maciel (2000),

[...] concretiza-se fundamentalmente, através do estabelecimento de novas relações pedagógicas entre o assistente social e os usuários de seus serviços. Relações estas favorecedoras de um processo de participação dos sujeitos envolvidos, numa dupla dimensão: de conhecimento crítico sobre a realidade e recursos institucionais tendo em vista a construção de estratégias coletivas em

Temporalis, Brasília (DF), ano 20, n. 39, p. 209-224, jan./jun. 2020. | ISSN 2238-1856 
atendimento as necessidades e interesses das classes subalternas; e de mobilização desses sujeitos, instrumentalização de suas lutas e manifestações coletivas na perspectiva do fortalecimento e avanço da organização das referidas classes como classe hegemônica (CARDOSO; MACIEL, 2000, p. 144).

Conforme afirma Almeida (2000),

[...] durante muitos anos a associação entre Serviço Social e educação esteve, quase que de forma automática, relacionada ou ao campo da formação profissional ou à dimensão educativa do trabalho dos assistentes sociais. As razões não nos são desconhecidas: uma franca alteração no perfil do mercado de trabalho, no que se tange à efetiva atuação dos assistentes sociais no âmbito dos estabelecimentos e da política educacional ao longo dos anos 70 e parte dos 80 , a afirmação do debate e das práticas sobre educação popular que se estenderam para além dos muros institucionais, além do reconhecido avanço teórico e político que as abordagens sobre a formação dos assistentes sociais ganharam no final deste século, particularmente face à atuação da Associação Brasileira de Ensino e Pesquisa em Serviço Social (ABEPSS) (ALMEIDA, 2000, p. 19-20).

Cabe ressaltar que a atuação profissional do/a assistente social na área da educação remonta aos primórdios da profissão, inclusive identificando-se com a nomenclatura Serviço Social Escolar, marcando sua trajetória nas primeiras décadas do Serviço Social no Brasil, com características próprias do momento histórico específico da gênese da profissão - portanto, travejado pela perspectiva conservadora.

Mas, no decorrer da década de 1990, há uma intensificação do debate sobre a educação e o Serviço Social na educação, que passa a adquirir maior visibilidade pela socialização de pesquisas e publicações, principalmente nos eventos próprios da categoria profissional, ou seja, no Congresso Brasileiro de Assistentes Sociais (CBAS) e no Encontro Nacional de Pesquisadores em Serviço Social (ENPESS).

Novamente nesta arena a ABEPSS, a ENESSO e, principalmente, o conjunto CFESS/CRESS, que, pela própria natureza de sua atuação, mobiliza esforços na busca pela inserção e consolidação do Serviço Social na política de educação brasileira.

É a partir dos anos 2000 que o tema Serviço Social na Educação é retomado na agenda de ações do conjunto CFESS/CRESS de forma mais incisiva, justamente por este estar sensível à ampliação dessa demanda profissional e à necessidade de adensar as discussões visando à consolidação gradativa desse campo de atuação profissional. Nesse sentido, Almeida (2004) comenta:

É de fundamental importância um amplo processo de mobilização da categoria profissional em torno deste tema, não só com o intuito de transformar expectativas em adesão, mas com o de instrumentalizar os assistentes sociais quanto ao significado político desta aproximação. Entendendo que o referido processo não diz respeito apenas ao âmbito do mercado de trabalho, mas ao conhecimento necessário sobre a educação, a política educacional e as possibilidades e demandas para a atuação dos assistentes sociais. Pode compor uma importante estratégia a organização de comissões de assistentes sociais que atuam, ou tenham proximidade e interesse nesta área, junto aos Conselhos Regionais de Serviço Social, conforme já ocorre em Minas Gerais e no Rio de Janeiro (ALMEIDA, 2004, p. 51). 


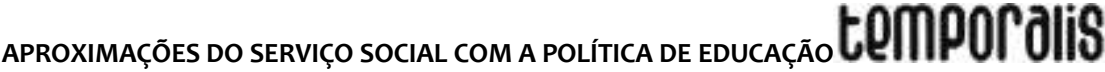

De acordo com Santos, Mesquita e Ribeiro (2012), ao traçar a trajetória histórica da mobilização do conjunto CFESS/CRESS em relação a essa questão, descreve-se que

\begin{abstract}
No $30^{\circ}$ Encontro Nacional do Conjunto CFESS-CRESS5 realizado em 2001, pela primeira vez, a categoria profissional elaborou propostas, de âmbito nacional, relacionadas à inserção do serviço social na Educação. Neste mesmo ano, foi constituído um Grupo de Estudos sobre o Serviço Social na Educação pelo CFESS, o qual construiu a brochura intitulada Serviço Social na Educação (CFESS, 2001). Neste documento, cujo objetivo foi contribuir com a discussão que se configurava no cenário nacional naquele momento, se problematizou a função social da escola, a Educação como um direito social, a contribuição do Serviço Social para a garantia do direito à educação e a escola como instância de atuação do/a assistente social. $O$ documento Serviço Social na Educação incorporou também o Parecer Jurídico $n^{\circ}$ 23/2000 elaborado pela assessora jurídica do CFESS, Sylvia Terra, sobre a implantação do Serviço Social nas escolas de Ensino Fundamental e Médio, relacionando sua pertinência a partir das atribuições atinentes à atividade profissional respectiva, estabelecida nos arts. $4^{\circ}$ e $5^{\circ}$ da Lei $n^{\circ}$ 8.662/1993. Tratou-se, também, das possibilidades legais dos projetos de lei para a implantação do Serviço Social nas escolas e da discussão sobre sua regulamentação nas instâncias de poder municipal e estadual (SANTOS, MESQUITA, RIBEIRO, 2012, p.249).
\end{abstract}

No período de 2001 a 2013, por meio do conjunto CFESS/CRESS, foram realizadas várias ações por todo o território nacional, destacando-se principalmente a criação dos Grupos de Trabalho (GT) ${ }^{2}$ a nível federal, que contou com a assessoria técnica do professor doutor Ney Luiz Teixeira de Almeida ${ }^{3}$. Esse GT do CFESS realizou uma pesquisa a nível nacional que, somada à contribuição da categoria profissional efetivada durante os seminários e debates ocorridos nos 23 (vinte e três) estados, sob a coordenação dos CRESS, e também no I Seminário Nacional de Serviço Social na Educação, realizado em Maceió (AL) em junho de 2012, culminou na elaboração do documento Subsídios para atuação de assistentes sociais na política de educação (CFESS, 2013) - documento que esteve sob assessoria, organização e sistematização do professor doutor Ney Luiz Teixeira de Almeida, ícone no estudo dessa temática.

A apresentação editada no documento explicita que o seu objetivo é:

contribuir para que a atuação profissional na Política de Educação se efetive em consonância com os processos de fortalecimento do projeto ético-político do serviço social e de luta por uma educação pública, laica, gratuita, presencial e de qualidade, que, enquanto um efetivo direito social, potencialize formas de sociabilidade humanizadoras (CONSELHO FEDERAL DE SERVIÇO SOCIAL, 2013, p. 7).

Alguns exemplos que marcam a significativa contribuição da categoria profissional em mobilizações com a sociedade civil organizada, conforme previsto nos princípios do Código de Ética Profissional do Assistente Social, são: os diversos posicionamentos públicos que

${ }^{2} \mathrm{O}$ GT foi composto por representantes de um CRESS de cada região do país e conselheiros do CFESS. A sua composição passou por alterações até o ano de 2012. O GT recebe assessoria do professor doutor Ney Luiz Teixeira de Almeida desde 2010 até a finalização do Documento: Subsídios para atuação de assistentes sociais na política de educação (publicação em 2013).

${ }^{3}$ Assistente social e professor da Faculdade de Serviço Social da UERJ. Mestre e doutor em Educação pela UFF. Autor de várias publicações sobre Serviço Social na Educação.

Temporalis, Brasília (DF), ano 20, n. 39, p. 209-224, jan./jun. 2020. | ISSN 2238-1856 
reafirmam a luta pela formação profissional de qualidade; as ações em prol da aprovação dos Projetos de Leis e/ou da Emenda Constitucional que propõe a inserção do Serviço Social na Educação (com destaque para o PL n. 3688/2000); o engajamento na luta por 10\% do PIB na educação; as ações que demonstram a incompatibilidade do ensino de graduação à distância (EAD); e a formação profissional em Serviço Social.

Nesse sentido,

\begin{abstract}
O Serviço Social brasileiro ousa dizer não à forma como vem sendo implementado o acesso da população brasileira ao ensino, que, em larga medida, extravia seu caráter público, presencial, laico e de qualidade, em um contexto neoliberal, no qual o Estado empenha-se para atender às exigências dos organismos internacionais, criando as condições para a institucionalização de um padrão educacional que dissemina uma educação que contribui para a manutenção da desigualdade social e de relações sociais que alienam, desumanizam e conferem adesão passiva ao modo de ser burguês (CONSELHO FEDERAL DE SERVIÇO SOCIAL, 2012, p. 5).
\end{abstract}

A afirmativa supracitada revela o posicionamento ético-político da categoria profissional de Assistentes Sociais no que tange à educação, porém é um exemplo do que, historicamente, sobretudo após o movimento de renovação da profissão, a categoria preconiza, de maneira pública, em relação a várias questões polêmicas que emergem no contexto brasileiro. Tais questões estão vinculadas à conjuntura proveniente da sociabilidade burguesa e do movimento que o capital tem assumido no final do século XX e início do século XXI, para garantir a acumulação capitalista, conforme citado anteriormente.

Portanto, a pauta do conjunto CFESS/CRESS não se restringe à defesa corporativa da categoria, seja pela ampliação dos espaços sócio-ocupacionais/maior volume de contratação, seja por melhores condições salariais e de trabalho. Ela é condizente também com um efetivo empenho em relação à formação e ao exercício profissional. De acordo com o projeto ético-político profissional, a direção das nossas lutas é ampliada e posta em consonância com a classe trabalhadora na defesa da equidade, liberdade e direitos humanos.

Retomando a interface do Serviço Social com a Política de Educação, Lessa (2013) traz interessante argumentação:

A relação entre o Serviço Social, a política educacional e a escola pública precisa ser compreendida em suas determinações de ordem econômica, social e política, considerando suas potencialidades e limitações no contexto do capitalismo neste novo milênio, que a despeito de seus avanços tecnológicos e de substituição do trabalho vivo pelo trabalho morto, para otimização dos processos de acumulação de capital, ainda precisa de uma educação que prepare homens e mulheres para seus processos de produção e reprodução social. Na realidade contemporânea, portanto, educar é uma tarefa central para o capitalismo, visto que este solicita uma formação propedêutica para uma minoria e um aprendizado simplificado e voltado para o mercado para as grandes massas populacionais (LESSA, 2013, p. 123).

Os assistentes sociais que atuam nessa política pública precisam inteirar-se do movimento contraditório que permeia as instituições educacionais e do trabalho coletivo desenvolvido 


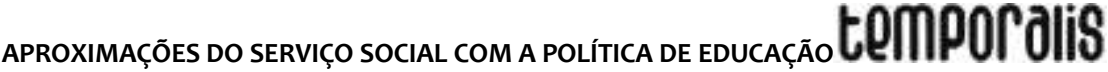

pelos profissionais da educação, para que, juntamente aos estudantes e suas famílias, possam identificar estratégias de ação capazes de tornar a educação mais efetiva - na perspectiva crítica e como um direito social.

É justamente nesse intuito que os assistentes sociais que atuam na área da política de educação precisam sintonizar-se com sujeitos coletivos: entidades representativas, movimentos sociais, conselhos de direitos para fortalecer a luta pela educação.

\begin{abstract}
As entidades representativas dos (as) assistentes sociais brasileiros vêm construindo sua organização política, no contexto atual, na perspectiva de estabelecer uma práxis política emancipatória, nos limites da sociabilidade do capital - em uma conjuntura de crise dos projetos societários emancipatórios; de refluxo dos movimentos sociais; de pauperização e desemprego da classe trabalhadora. A ação política destas entidades tem se constituído em um dos fatores que garantem a possibilidade de manutenção da direção social do projeto profissional vinculado aos interesses do trabalho (RAMOS, 2006, apud, RAMOS, 2011, p. 121).
\end{abstract}

Dessa forma, o Grupo de Estudos e Pesquisas sobre Serviço Social na Educação ${ }^{4}$ reconhece o empenho das entidades representativas da categoria profissional, especificamente em relação à agenda de lutas empreendidas em prol da política de educação como direito social, e entende a necessidade da argumentação explicitada para desvelar a real contribuição do Serviço Social na área da educação.

Acredita-se não ser possível falar sobre o Serviço Social na Educação sem trazer à cena a efetiva contribuição do conjunto CFESS/CRESS, desenvolvida não só na articulação, na mobilização e na luta pela política de educação como direito social, mas também na tentativa de inserir o assistente social nesse espaço sócio-ocupacional. Reconhecendo essa valiosa contribuição, o último item deste capítulo resgata a trajetória histórica da sintonia do conjunto CFESS/CRESS com o tema Serviço Social na Educação.

\section{A ATUAÇÃO DAS COMISSÕES DE EDUCAÇÃO DOS CONSELHOS REGIONAIS DE SERVIÇO SOCIAL NO BRASIL}

A presença de assistentes sociais na política de educação acompanha toda a história do Serviço Social no Brasil; entretanto, a década de 1990 é demarcada como um divisor de águas nesse processo, pelo considerável aumento do Serviço Social na área da educação.

Assim, podemos afirmar que a partir da década de 1990 ocorre a expansão/consolidação da área da educação como campo de atuação do assistente social. Nesse sentido, e acompanhando esse processo, "[...] em muitos estados as particularidades da intervenção do Serviço Social na Educação ganharam destaque nos espaços de organização e na agenda de nossa categoria profissional" (CONSELHO FEDERAL DE SERVIÇO SOCIAL, 2012,

\footnotetext{
${ }^{4}$ Considerando que há poucos Grupos de Estudos e Pesquisas sobre Serviço Social na Educação (de acordo com o Diretório de Grupos de Pesquisa do CNPq, somente dois) o GEPESSE está ativo em três Universidades, sendo: UNESP/Campus de Franca (coordenação Dra. Eliana Bolorino Canteiro Martins, UERJ/Rio de Janeiro (coordenação Dr. Ney Luiz Teixeira de Almeida e UFBA/Bahia (coordenadora Dra. Adriana Freire Pereira Férriz.
}

Temporalis, Brasília (DF), ano 20, n. 39, p. 209-224, jan./jun. 2020. | ISSN 2238-1856 
p. 4). O Conjunto CFESS-CRESS assume, então, um papel de suma importância ao motivar a criação das Comissões Temáticas de Educação nos CRESS, e com isso dá início às discussões, aos debates e às proposições nos encontros nacionais da categoria sobre a temática do Serviço Social na educação.

De acordo com o CFESS (2019),

[...] O Brasil tem hoje aproximadamente 180 mil profissionais, que atuam, predominantemente, na formulação, planejamento e execução de políticas públicas como educação, saúde, previdência, assistência social, habitação, transporte, entre outras, movidos/as pela perspectiva de defesa e ampliação dos direitos da população brasileira. Trabalham também na esfera privada, principalmente, no âmbito do repasse de serviços, benefícios e na organização de atividades vinculadas à produção material, e atuam em processos de organização e formação política de segmentos da classe trabalhadora (CONSELHO FEDERAL DE SERVIÇO SOCIAL, 2019, p. 1).

Esses dados exorbitantes sobre o número de profissionais nos dias atuais vêm mobilizando a categoria há alguns anos. Nesse sentido, o CFESS conta com uma comissão de formação profissional e relações internacionais que atua na perspectiva de "[...] fortalecer a articulação entre a formação e o exercício profissional, estimulando a criação de mecanismos para qualificação profissional como requisito para valorização da profissão" (CONSELHO FEDERAL DE SERVIÇO SOCIAL, 2019, p. 1). Além disso, o CFESS conta com uma comissão de seguridade social que defende a intervenção qualificada e crítica dos/as assistentes sociais como trabalhadores/as que atuam em todas as políticas sociais e em diversos campos sócio-ocupacionais, formulando respostas às múltiplas expressões da questão social que constituem objeto de trabalho profissional, nas diversas políticas de trabalho e emprego, habitação e educação, na perspectiva de estabelecimento de um padrão universal de direitos e políticas públicas.

A nossa intenção com este texto foi verificar como os CRESS estão lidando com a temática da inserção do assistente social na educação nos dias atuais e, consequentemente, se as comissões de educação dos CRESS continuam em atividade na luta pela defesa da educação e pela inserção do assistente social na educação.

Para tanto, entramos em contato com os CRESS das 27 regionais do CFESS. A aproximação inicial foi feita diretamente aos CRESS, por meio das informações disponibilizados no site do CFESS. Em seguida, foram usadas outras estratégias, tomando como base contatos de profissionais que atuam na área da educação em várias regionais.

O levantamento junto aos CRESS revelou a seguinte configuração: 1. CRESS que possuem comissões específicas de educação; 2. CRESS que não têm comissão de educação, mas que contam com grupos de trabalho que discutem o tema da educação; 3. CRESS que não têm comissão de educação, mas que as discussões concernentes à temática da educação são realizadas nas comissões de formação profissional ou de seguridade social; e 4. CRESS que não têm comissão de educação ativa no momento e que não têm outro espaço de discussão do assunto. 


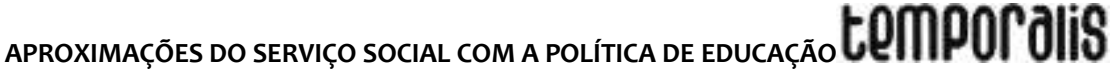

Quadro 1 - Configuração atual das comissões de educação dos CRESS
\begin{tabular}{|l|l|}
\hline CRESS & Situação da comissão de educação \\
\hline $1^{\circ}$ Região - Belém/PA & Comissão de educação ativa \\
\hline $2^{\circ}$ Região - São Luís/MA & Comissão de educação ativa \\
\hline $3^{\circ}$ Região - Fortaleza/CE & Grupo de trabalho de educação \\
\hline $4^{\circ}$ Região - Recife/PE & Não possui \\
\hline $5^{\circ}$ Região - Salvador/BA & Comissão de educação ativa \\
\hline $6^{\circ}$ Região - Belo Horizonte/MG & Comissão de educação ativa \\
\hline $7^{\circ}$ Região - Rio de Janeiro/RJ & Comissão de educação ativa \\
\hline $8^{\circ}$ Região - Brasília/DF & Comissão de formação profissional \\
\hline $9^{\circ}$ Região - São Paulo/SP & Comissão de formação profissional \\
\hline & $\begin{array}{l}\text { Comissão de formação profissional e Grupo de trabalho } \\
\text { de educação }\end{array}$ \\
\hline $10^{\circ}$ Região - Porto Alegre/RS & Câmara temática de Serviço Social na Educação \\
\hline $11^{\circ}$ Região - Curitiba/PR & Comissão de educação ativa \\
\hline $12^{\circ}$ Região - Florianópolis/SC & Comissão de educação ativa \\
\hline $13^{\circ}$ Região - João Pessoa/PB & Comissão de formação profissional e de seguridade \\
\hline & social \\
\hline $14^{\circ}$ Região - Natal/RN & Não possui \\
\hline $15^{\circ}$ Região - Manaus/AM & Não possui \\
\hline $16^{\circ}$ Região - Maceió/AL & Comissão de formação profissional \\
\hline $17^{\circ}$ Região - Vitória/ES & Comissão de educação ativa \\
\hline $18^{\circ}$ Região - Aracaju/SE & Não possui \\
\hline $19^{\circ}$ Região - Goiânia/GO & Comissão de Formação Profissional \\
\hline $20^{\circ}$ Região - Cuiabá/MT & Comissão de Formação Profissional \\
\hline $21^{\circ}$ Região - Campo Grande/MS & Não possui \\
\hline $22^{\circ}$ Região - Teresina/PI & Comissão de educação ativa \\
\hline $23^{\circ}$ Região - Porto Velho/RO & Não tivemos acesso às informaçães \\
\hline $24^{\circ}$ Região - Macapá/AP & Comissão de Formação Profissional \\
\hline $25^{\circ}$ Região - Palmas/To & Não possui \\
\hline $26^{\circ}$ Região - Rio Branco/AC & Não possui \\
\hline $27^{\circ}$ Região - Boa Vista/RR & \\
\hline Fonte: & \\
\hline
\end{tabular}

Fonte: Elaboração das autoras, 2019.

As regionais dos CRESS que possuem comissões específicas de educação ativas são 9 (nove), a saber, $1^{\circ}$ Região - Belém/PA, $2^{\circ}$ Região - São Luís/MA, $5^{\circ}$ Região - Salvador/BA, $6^{\circ}$ Região - Belo Horizonte/MG, $7^{\circ}$ Região - Rio de Janeiro/RJ, $12^{\circ}$ Região - Florianópolis/SC, $13^{\circ}$ Região - João Pessoa/PB, $18^{\circ}$ Região - Aracaju/SE e $23^{\circ}$ Região - Porto Velho/RO.

Os CRESS das regionais $8^{\circ}$ Região - Brasília/DF, $9^{\circ}$ Região - São Paulo/SP, $10^{\circ}$ Região - Porto Alegre/RS, $14^{\circ}$ Região - Natal/RN, $17^{\circ}$ Região - Vitória/ES, $20^{\circ}$ Região - Cuiabá/MT, $21^{\circ}$ Região - Campo Grande/MS e $25^{\circ}$ Região - Palmas/Tocantins têm comissão de educação, mas as discussões concernentes à temática da educação são realizadas nas comissões de formação profissional e/ou de seguridade social.

Há também as regionais que não têm comissão de educação, mas que realizam as discussões sobre a atuação dos profissionais na política de educação por meio de grupos (de trabalho e/ou da Câmara temática de Serviço Social na Educação) que se empenham no processo de reflexão sobre o tema da educação, como é o caso das regionais $3^{\circ}$ Região - Fortaleza/CE e $11^{\circ}$ Região - Curitiba/PR.

No que se refere aos CRESS que não têm comissão de educação ativa no momento e que não possuem outro espaço de discussão do assunto, foram identificadas 7 (sete) regionais,

Temporalis, Brasília (DF), ano 20, n. 39, p. 209-224, jan./jun. 2020. | ISSN 2238-1856 
a saber: $4^{\circ}$ Região - Recife/PE, $15^{\circ}$ Região - Manaus/AM, $16^{\circ}$ Região - Maceió/AL, $19^{\circ}$ Região Goiânia/GO, $22^{\circ}$ Região - Teresina/PI, $26^{\circ}$ Região - Rio Branco/AC e $27^{\circ}$ Região - Boa Vista/RR.

Gostaríamos de destacar a importância dos espaços existentes nos CRESS que se dedicam à discussão e à luta pela inserção de assistentes sociais na política de educação, seja por meio de comissões formadas exclusivamente para essa função, seja por meio de comissões mais amplas (como a comissão de seguridade social e de formação profissional), seja a partir de grupos de trabalho temporários que se dedicam ao tema.

\title{
4 CONSIDERAÇÕES FINAIS
}

A educação é uma dimensão da vida humana, e a educação escolarizada no Brasil traz a marca inerente à educação, ou seja, a contradição - na medida em que dissemina a ideologia dominante e prepara o trabalhador para o mercado de trabalho abstrato de acordo com a necessidade de cada momento histórico, além de perpetuar a dualidade educacional, dividindo-a em uma educação para os burgueses e outra para os trabalhadores. Porém, também é o espaço de apropriação de conhecimentos científicos socialmente produzidos pela humanidade. É, aliás, justamente nesse espaço tensionado de interesses contraditórios das classes fundantes (capital e trabalho) que há a possibilidade de a classe trabalhadora acessar os elementos intelectuais que the serão de grande ajuda na compreensão da própria realidade social, permitindo o desenvolvimento de uma consciência crítica. A afirmação de Paulo Freire ilustra essa perspectiva de análise:

\begin{abstract}
Acreditamos que a educação sozinha não transforma a sociedade, mas sem ela tampouco a sociedade muda. Se a nossa opção é progressista, se estamos a favor da vida e não da morte, da equidade e não da injustiça, do direito e não do arbítrio, da convivência com o diferente e não de sua negação, não temos outro caminho se não viver a nossa opção, encarná-la, diminuindo, assim a distância entre o que dizemos e o que fazemos (FREIRE, 1996, p. 32).
\end{abstract}

Partindo desses pressupostos, a categoria dos profissionais de Serviço Social, por meio dos seus órgãos representativos - conjunto CFESS/CRESS, ABEPSS e também a ENESSO -, reafirma o compromisso de luta pelos direitos da classe trabalhadora, resistindo às ofensivas do capital, de forma particular, pela educação como parte integrante de uma seguridade social ampliada. O empenho na conquista da inserção do Assistente Social na organização do trabalho coletivo nas diferentes instituições educacionais remete ao reconhecimento de que a educação envolve relações sociais e processos interinstitucionais, familiares e territoriais; assim, o assistente social possui competência teórico-metodológica, técnico-operativa e ético-política acumulada na sua formação profissional, que, por ser diferente da dos profissionais da educação, permite a possibilidade de uma contribuição significativa.

Diante do exposto, acreditamos na relevância da articulação do conjunto CFESS/CRESS, por intermédio das Comissões que envolvam o debate sobre o Serviço Social na Educação, constituindo-se em uma força de sujeitos coletivos, pois a experiência sócio-profissional já comprovou que é necessário um corpo profissional fortemente organizado para enfrentar os desafios postos pela realidade, principalmente em tempos de crise do capital e da forte onda neoconservadora que assola a realidade brasileira, com reflexos assustadores na política educacional. 


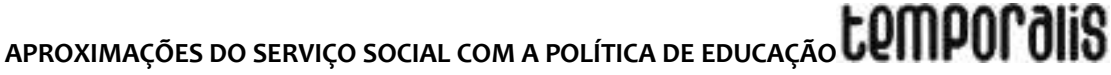

É importante frisar que, mesmo diante de enormes adversidades, os órgãos representativos dessa categoria profissional - o conjunto CFESS/CRESS; a ABEPSS; e, inclusive, os estudantes, por meio da ENESSO - não se intimidam nos seus posicionamentos e na defesa intransigente dos direitos humanos e sociais, confirmando cotidianamente que realmente essa é uma profissão forjada na luta e na resistência. Conclamamos neste singelo artigo o fortalecimento das Comissões de Serviço Social na educação do conjunto CFESS/CRESS como importante espaço de reflexão das diversas dimensões do trabalho profissional do assistente social; análises sobre a política de educação em todos os níveis e modalidades de ensino; articulação com os movimentos sociais em prol da educação; e mobilização de estratégias para o fortalecimento da categoria profissional de assistentes sociais.

\section{REFERÊNCIAS}

ASSOCIAÇÃO BRASILEIRA DE ENSINO E PESQUISA EM SERVIÇO SOCIAL. Projeto ABEPSS Itinerante. Brasília (DF), 2018. Disponível em: http://www.abepss.org.br/projeto-abepssitinerante-18. Acesso em: 20 jan. 2019.

ALMEIDA, N. L. T. Debate crítico: Serviço Social, política de Educação e questões societárias. In: FÓRUM DO SERVIÇO SOCIAL NA EDUCAÇÃO, 2., 2011, São Paulo. Anais [...]. 8. ed. São Paulo: UNESP, 2011 (Apresentação p. 5-7).

ALMEIDA, N. L. T. "O Serviço Social na educação". Revista Inscrita, Brasília: CFESS, n. 6, p. 19-24, 2000.

ALMEIDA, N. L. T. Parecer sobre os projetos de lei que dispõem sobre a inserção do Serviço Social na Educação. Brasília (DF): Conselho Federal de Serviço Social, 2004. Disponível em: www.assistentesocial.com.br/novosite/caderno/cadesp.26.pdf. Acesso em: 20 de fev. 2019.

BRASIL. Lei n. 8.662/93 de regulamentação da profissão. 9. ed. rev. e atual. [Brasília (DF)]: Conselho Federal de Serviço Social, [2011]. Disponível em: http://www.cresses.org.br/site/index.php?option=com_content\&view=article\&id=69\&ltemid=78. Acesso em: 16 jan. 2019.

CARDOSO, F. G.; MACIEL, M. Mobilização social e práticas educativas. Cadernos Capacitação em Serviço Social e política social, Brasília (DF): CEAD, mod. 4., p.139-149, 2000.

CONSELHO FEDERAL DE SERVIÇO SOCIAL. Subsídios para o debate do Serviço Social na Educação (título provisório). Grupo de Trabalho Serviço Social na Educação. Brasília (DF), 2012.

CONSELHO FEDERAL DE SERVIÇO SOCIAL. Endereço dos CRESS e seccionais. Disponível em: http://www.cfess.org.br. Acesso em: 20 jan. 2019.

CONSELHO FEDERAL DE SERVIÇO SOCIAL. Documento: Subsídios para atuação do Serviço Social na educação. Brasília (DF), 2013.

Temporalis, Brasília (DF), ano 20, n. 39, p. 209-224, jan./jun. 2020. | ISSN 2238-1856 
FREIRE, Paulo. Pedagogia da autonomia: Saberes necessários à prática educativa. 29. ed. Rio de Janeiro: Paz e Terra, 1996.

IAMAMOTO, M. V. CARVALHO, R. Relações sociais e Serviço Social no Brasil: esboço de uma interpretação histórico-sociológica. São Paulo: Cortez; Celats, 1982.

LESSA, S.E.C. A educação contemporânea, o combate à pobreza e as demandas para o trabalho do assistente social: contribuição para este debate. Serviço Social Sociedade, São Paulo, n. 113, p. 106-130, jan./mar. 2013.

NETTO, J.P. A. construção do projeto ético-político contemporâneo. In: CAPACITAÇÃO em Serviço Social e Política Social. Módulo 1. Brasília (DF): CEAD; ABEPSS; CFESS, 1999.

RAMOS, R. S. Organização política dos(as) assistentes sociais brasileiros(as): a construção histórica de um patrimônio coletivo na defesa do projeto profissional. Serviço Social e Sociedade, São Paulo, n. 88, 2006.

RAMOS, R. R. A importância da articulação entre ABEPSS, conjunto CFESS/CRESS E ENESSO para a construção do projeto ético político do serviço social brasileiro. Temporalis, Brasília (DF), ano 11, n. 22, p. 113-122, jul./dez. 2011.

SANTOS, M. E; MESQUITA, M; RIBEIRO, A. A inserção do Serviço Social na Política de Educação na perspectiva do Conjunto CFESS/CRESS: elementos históricos e desafios para a categoria profissional. Revista Ser Social, Brasília (DF), v. 14, n. 30, p. 244-258, jan./jun. 2012.

\footnotetext{
Adriana Freire Pereira FÉRRIZ trabalhou na elaboração do texto

Assistente social. Pós-doutorado (2018) pela Universidade Estadual do Rio de Janeiro (UERJ) tendo como tema da investigação $O$ trabalho do assistente social na educação básica nos estados da Paraíba e da Bahia, supervisionada pelo Prof. Dr. Ney Luiz Teixeira de Almeida. Doutorado em Sociologia pela Universidade Federal da Paraíba (2012), mestrado em Sociologia Rural pela Universidade Federal da Paraíba (2004) e graduação em Serviço Social pela Universidade Estadual da Paraíba (2002). Atualmente, é docente da graduação em Serviço Social e do Programa de Pós-Graduação em Serviço Social (PPGSS) da Universidade Federal da Bahia (UFBA), coordenadora do Programa Nacional de Capacitação do Sistema Único de Assistência Social (CapacitaSUAS) e responsável pelo Grupo de Estudos e Pesquisas sobre Serviço Social na área da Educação (GEPESSE), na UFBA.
}

Eliana Bolorino Canteiro MARTINS trabalhou na elaboração do texto

Assistente social. Pós-doutorado (2019) pela UERJ tendo como tema da investigação O trabalho do assistente social na educação básica no estado de São Paulo, supervisionada pelo Prof. Dr. Ney Luiz Teixeira de Almeida. Doutorado em Serviço Social pela Pontifícia Universidade Católica de São Paulo - PUC/SP (2007), mestrado em Serviço Social pelo Programa de Pós-Graduação em Serviço Social, Universidade Estadual Paulista (UNESP) Faculdade de Ciências Humanas e Sociais- Campus Franca (2001) e graduação em Serviço Social pela Faculdade de Serviço Social - Instituição Toledo de Ensino de Bauru (1983). Atualmente, é docente do curso graduação em Serviço Social da Universidade Estadual Paulista (UNESP) Faculdade de Ciências Humanas e Sociais/Campus Franca (2010-atual), Membro do corpo docente do Programa de Pós-Graduação em Serviço social da Universidade Estadual Paulista (UNESP- Campus Franca). Líder do Grupo de Estudos e Pesquisa sobre Serviço Social na Educação (GEPESSE), Vice-líder do Grupo de Estudos e Pesquisas sobre Políticas Públicas da Infância e Adolescência (GEPPIA), Bolsista Produtividade em pesquisa do CNPq - nível 2. 